\title{
Impact of ZBTB7A hypomethylation and expression patterns on treatment response to hydroxyurea
}

Vasiliki Chondrou ${ }^{1 \dagger}$, Eleana F. Stavrou ${ }^{1 \dagger}$, Georgios Markopoulos ${ }^{2}$, Alexandra Kouraklis-Symeonidis ${ }^{3}$, Vasilios Fotopoulos ${ }^{4}$, Argiris Symeonidis ${ }^{5}$, Efthymia Vlachaki ${ }^{6}$, Panagiota Chalkia ${ }^{7}$, George P. Patrinos ${ }^{8}$, Adamantia Papachatzopoulou ${ }^{9}$ and Argyro Sgourou ${ }^{1 *}$

\begin{abstract}
Background: We aimed to clarify the emerging epigenetic landscape in a group of genes classified as "modifier genes" of the $\beta$-type globin genes (HBB cluster), known to operate in trans to accomplish the two natural developmental switches in globin expression, from embryonic to fetal during the first trimester of conception and from fetal to adult around the time of birth. The epigenetic alterations were determined in adult sickle cell anemia (SCA) homozygotes and SCA $\beta$-thalassemia compound heterozygotes of Greek origin, who are under hydroxyurea $(\mathrm{HU})$ treatment. Patients were distinguished in $\mathrm{HU}$ responders and $\mathrm{HU}$ non-responders (those not benefited from the $\mathrm{HU}$ ) and both, and in vivo and in vitro approaches were implemented.
\end{abstract}

Results: We examined the CpG islands' DNA methylation profile of BCL11A, KLF1, MYB, MAP3K5, SIN3A, ZBTB7A, and GATA2, along with $\gamma$-globin and LRF/ZBTB7A expression levels. In vitro treatment of hematopoietic stem cells (HSCs) with HU induced a significant DNA hypomethylation pattern in ZBTB7A $\left(p^{*}, 0.04\right)$ and GATA2 $\left(p^{*}, 0.03\right)$ CpGs exclusively in the HU non-responders. Also, this group of patients exhibited significantly elevated baseline methylation patterns in ZBTB7A, before the HU treatment, compared to HU responders $\left(p^{*}, 0.019\right)$ and to control group of healthy individuals $\left(p^{*}, 0.021\right)$ , which resembles a potential epigenetic barrier for the $\gamma$-globin expression. $\gamma$-Globin expression in vitro matched with detected HbF levels during patients' monitoring tests (in vivo) under HU treatment, implying a good reproducibility of the in vitro HU epigenetic effect. LRF/ZBTBTA expression was elevated only in the HU non-responders under the influence of $\mathrm{HU}$.

Conclusions: This is one of the very first pharmacoepigenomic studies indicating that the hypomethylation of ZBTB7A during $\mathrm{HU}$ treatment enhances the LRF expression, which by its turn suppresses the $\mathrm{HbF}$ resumption in the HU nonresponders. Its role as an epigenetic regulator of hemoglobin switching is also supported by the wide distribution of ZBTB7A-binding sites within the 5' CpG sequences of all studied human HBB cluster "modifier genes." Also, the baseline methylation level of selective CpGs in ZBTB7A and GATA2 could be an indicator of the negative HU response among the $\beta$-type hemoglobinopathy patients.

Keywords: SCA homozygotes, SCA/ $\beta$-thal heterozygotes, Hydroxyurea treatment, HbF induction, HBB cluster "modifying genes", Epigenetic regulation

\footnotetext{
* Correspondence: sgourou@eap.gr

† Vasiliki Chondrou and Eleana F. Stavrou contributed equally to this work.

${ }^{1}$ School of Science and Technology, Biology Laboratory, Hellenic Open

University, Patras, Greece

Full list of author information is available at the end of the article
}

(c) The Author(s). 2018 Open Access This article is distributed under the terms of the Creative Commons Attribution 4.0 International License (http://creativecommons.org/licenses/by/4.0/), which permits unrestricted use, distribution, and reproduction in any medium, provided you give appropriate credit to the original author(s) and the source, provide a link to the Creative Commons license, and indicate if changes were made. The Creative Commons Public Domain Dedication waiver (http://creativecommons.org/publicdomain/zero/1.0/) applies to the data made available in this article, unless otherwise stated. 


\section{Introduction}

Thalassemias and sickle cell anemia (SCA) are still of the most common genetic disorders among human population even after many decades of worldwide prenatal control attempts. Furthermore, the combination of $\beta^{\mathrm{s}}$ allele, as a consequence of the SCA genotype with $\beta$-thalassemic alleles (SCA/ $\beta$-thal), appears with an evenly severe clinical phenotype. Clinical practice has shown that, despite identical disease-causing mutations, the pathological phenotype of disease varies enormously between individual patients. This is partly related to genetic variants of the genetic loci coding for the hemoglobin subunits alpha and beta $(H B A$ and $H B B)$ including their remote regulatory regions (LCRs-locus control regions) $[1,2]$ and the co-interaction with other parameters such as epigenetic regulatory mechanisms [3].

These genetic disorders have an early onset, within a few months after birth, which is accompanied by high financial burdens to healthcare systems due to the expensive therapeutic protocols applied to patients. Apart from the regular blood transfusions and iron-chelating agents, an alternative widely used therapeutic approach is the induction of fetal hemoglobin ( $\mathrm{HbF}$ ) expression that ameliorates their pathological phenotype $[4,5]$. Hydroxyurea (HU) or hydroxycarbamide is the major therapeutic agent identified as a potent $\mathrm{HbF}$ inducer and has been used for the management of patients with SCA and SCA/ $\beta$-thal, since its FDA approval in1998 [6, 7]. The main mechanism of $\mathrm{HU}$ action is the inhibition of the ribonucleotide reductase (RR), which pauses the DNA synthesis. The in vivo effects of HU in mammalian systems are transient, as a consequence from the rapid absorption, metabolism, and excretion of the drug. Once-daily dosing of HU presumably causes an intermittent cytotoxic effect resulting in stress erythropoiesis and increased HbF levels [8]. Patients administered with $\mathrm{HU}$ show elevated $\mathrm{HbF}$ levels within the first 3 to 6 months of treatment, with further improvements up to 12 months, where patients reach a plateau with the maximum $\mathrm{HbF}$ expression levels and the corresponding maximum mean erythrocyte corpuscular volume (MCV) [9]. However, HbF levels do not present a uniform increase in all patients, whereas long-term use of $\mathrm{HU}$ sometimes leads to the loss of its initial beneficial action $[10,11]$. The underlying precise molecular mechanism of the $\mathrm{HU}$ action and the variance of treatment results remain still elusive, though a concealed epigenetic effect of its action is highly suspected.

Epigenetic modifications, such as DNA methylation and histone methylation/acetylation, constitute an additional layer of gene expression regulation and affect phenotypic heterogeneity of human diseases and drug responses $[12,13]$. DNA methylation mainly occurs in the context of CG dinucleotides (CpGs) and has traditionally been associated with gene repression [14].

This study concerns the methylation alterations, induced by $\mathrm{HU}$ treatment on known $\beta$-type globin genes (HBB cluster) "modifier genes":erythroid-specific transcription factors (KLF1, GATA1, and GATA2), regulators of hematopoiesis and erythropoiesis (MYB, SOX6, $S I N 3 A)$, members of the MAPK signaling pathway (MAP3K5), and $\mathrm{HbF}$ repressors (BCL11A, ZBTB7A) [15-28], in terms of contributing to knowledge on the molecular epigenetic regulation of embryonic $\mathrm{HbF}\left(\alpha_{2} \gamma_{2}\right)$ reactivation during the human progenitor cells' exposure to HU. Though SOX6 and GATA1 bared no CpG islands within neighboring sequences, indicating that they are alternatively regulated and were excluded from the study, CpG islands' quantitative analysis of hyper- or hypomethylation status within the $H B B$ cluster "modifier genes" has been elaborated both in patients comprised within a long-term treatment and newly introduced to HU. The epigenetic landscape of these genes has also been studied during cultivation and erythroid differentiation of human-induced hematopoietic pluripotent stem cells derived from healthy donors' and patients' peripheral blood, cord blood, and bone marrow, under the pressure of $\mathrm{HU}$ to simulate in vitro the pharmacological induction of $\mathrm{HbF}$ and the corresponding cell molecular responses.

The aim of our study was to depict and highlight changes in the DNA methylation pattern at genomic loci unlinked to the $H B B$ cluster on chromosome 11, which may influence the $\mathrm{HbF}$ induction in adults, to distinguish the different epigenetic regulatory nuclear mechanisms acting among responders and non-responders to treatment with $\mathrm{HU}$ and to contribute to the development of a clinical algorithm for improved prediction of the patients' response to HU treatment.

\section{Material and methods \\ Bioinformatics analysis and CpG islands' selection}

Candidate disease identified "modifier loci," encoding $\beta$-type globin gene regulators were: $B C L 11 A, K L F 1$, $M Y B, M A P 3 K 5, S O X 6, S I N 3 A, Z B T B 7 A, G A T A 1$, and GATA2 [15-28]. CpG islands of all genes were retrieved by the UCSC genome browser (genome.ucsc.edu) [29]. Selected CpG islands for the study are located at areas flanking genes' promoter or within downstream 5' UTR regions and gene bodies. Respective data for gene locations and CpG islands analyzed are presented in Table 1. All include sites for CTCF and/or ZBTB7A transcription factors' commitment (Fig. 1). Genes and/or CpG sites that did not preserve these characteristics were excluded from the study.

Transcription factor binding sites for CTCF and ZBTB7A were extracted from ENCODE project Chip-Seq data [30] and visualized in the UCSC genome browser. 
Table 1 Chromosomal locations of all CpG islands analyzed

\begin{tabular}{|c|c|c|c|}
\hline Gene & Location of CpG island & CTCF-binding site & ZBTB7A-binding site \\
\hline \multirow[t]{3}{*}{$B C L 11 A$} & CpG 120 & + & - \\
\hline & Chr2: 60554555-60554409 & & \\
\hline & Chr2: 60554304-60554174 & & \\
\hline \multirow[t]{2}{*}{$B C L 11 A$} & CpG 115 & + & + \\
\hline & Chr 2: 60550535-60550416 & & \\
\hline \multirow[t]{3}{*}{ KLF1 } & CpG 98 & + & - \\
\hline & Chr 19: 12885764-12885569 & & \\
\hline & Chr 19: 12885322-12885477 & & \\
\hline \multirow[t]{3}{*}{ MYB } & CpG 216 & - & - \\
\hline & Chr 6: 135181253-135181153 & & \\
\hline & Chr 6: 13518140-135181107 & & \\
\hline \multirow[t]{2}{*}{$\operatorname{SIN} 3 A$} & CpG 401 & + & + \\
\hline & Chr 15: 75454578-75454439 & & \\
\hline \multirow[t]{3}{*}{ ZBTB7A } & CpG 326 & - & + \\
\hline & Chr 19: 4067422-4067286 & & \\
\hline & Chr 19: 4066671-4066789 & & \\
\hline \multirow[t]{2}{*}{ GATA2 } & CpG 515 & - & + \\
\hline & Chr 3: $128488082-128487980$ & & \\
\hline \multirow[t]{2}{*}{ MAP3K5 } & CpG 172 & + & + \\
\hline & Chr 6: 136792589-136792545 & & \\
\hline
\end{tabular}

\section{Sample collection}

Patients were selected based on the existence of homozygosity to $\mathrm{HbS}$ (SCA) or compound heterozygosity to SCA and $\beta$-thalassemia (SCA/ $\beta$-thal). All patients were adults, either treated for long-term with $\mathrm{HU}$ or for immediate treatment initiation, due to life-threatening disease-related symptoms. For the newly introduced patients to $\mathrm{HU}$ therapy, the mean dosage of $\mathrm{HU}$ administered was $20 \mathrm{mg} / \mathrm{kg}$ and the mean follow-up time was 5-6 months. Upon arrival to the plateau phase, where maximum $\mathrm{HbF}$ was produced, patients continued to be monitored annually. HbF levels at baseline and 5-6 months after initiation of $\mathrm{HU}$ treatment were estimated in all patients participating in this study with the high-performance liquid chromatography (HPLC) method, $\mathrm{HbA}_{2} / \mathrm{HbA}_{1 \mathrm{c}}$ dual program (VARIANT ${ }^{\mathrm{Tm}}$ II Beta-Thalassemia, Bio-Rad) (Additional file 1: Figure S1). Patients' hematological data are presented in Additional file 1: Table S1.

Blood samples of SCA, SCA/ $\beta$-thal, and healthy donors have been included in the study. Experimental procedures have been applied both in vivo and in vitro.

Samples analyzed in vivo were group $\mathrm{I}-30$ peripheral blood samples from SCA and SCA/ $\beta$-thal patients, sub-categorized to responders and non-responders to HU (Additional file 1: Table S1), and group II-20 peripheral blood samples from healthy donors to act as reference group.

Samples analyzed in vitro were as follows: Group IIIburst-forming unit-erythroid (BFU-E) cell populations from hematopoietic progenitor human cells acquired from the peripheral blood of selected SCA/ $\beta$-thal patients who were undergoing $\mathrm{HU}$ therapy for the first time. Total samples cultivated derived from five responders (III R1-R5) and for non-responders (III NR1NR4). Their characterization as responsive or not to the HU treatment was done later, when they had reached the plateau phase (5-6 months). III NR3 and NR4 were sisters and brothers. Group IV-BFU-E colonies acquired from peripheral blood of the control group (four samples IV CG1-CG4), from the bone marrow (four samples, IV BM1-BM4), and from the umbilical cord blood (four samples, IV UCB1-UCB4), all coming from healthy donors (Table 2).

Responders and non-responders to HU were clinically distinguished in relevance to their hematological parameters before and after administration of $\mathrm{HU}$, their transfusion needs, and the capability to ameliorate anemia symptoms. For the present study, which focused on the epigenetic regulatory differences among the $H B B$ cluster "modifier genes" and their influence in $\mathrm{HbF}$ induction, the strict clinical evaluation of 


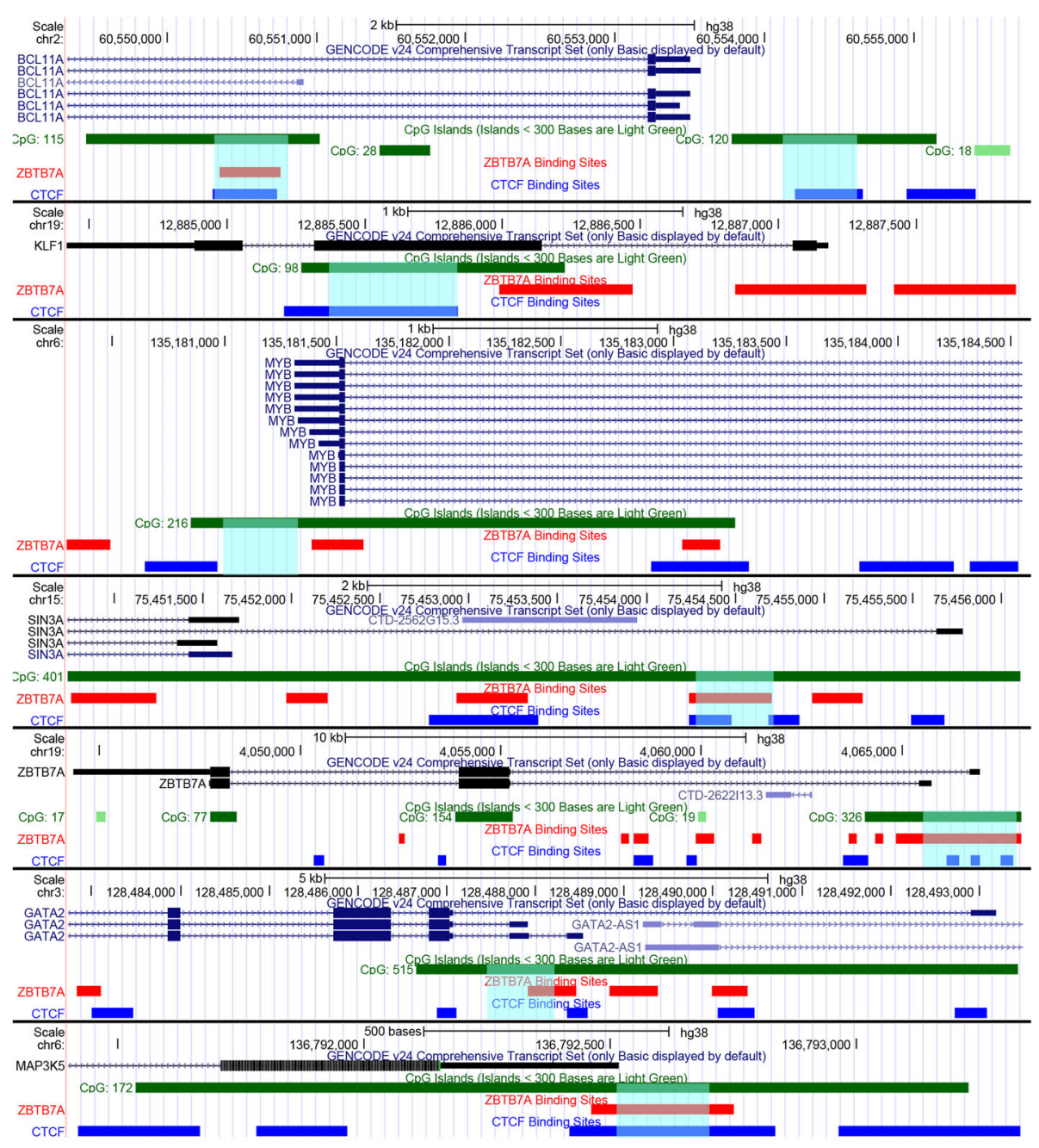

Fig. 1 Epigenetic features of promoter regions of genes analyzed in this study. The promoter regions and sequence features of $B C L 11 A$, KLF1, MYB, SIN3A, ZBTB7A, GATA2, and MAP3K5 respectively are presented in parallel tracks, from top to bottom: scale, chromosomal location, gene transcript from Gencode v.24 (exons are represented as boxes and introns as lines with arrows indicating the $5^{\prime}$ towards the $3^{\prime}$ region), CpG islands (boxes in green color), LRF/ ZBTB7A-binding sites (boxes in red color), and CTCF-binding sites (boxes in blue color). Chromosomal locations of interest in each promoter region are highlighted with light blue transparent boxes

patients has not been applied. Responders were considered the patients with an overall improved disease course and $\mathrm{a} \geq 2.5$-fold $\mathrm{HbF}$ increase.

Hematopoietic stem cells from categories III and IV have been cultivated simultaneously in the presence and absence of HU (50-100 $\mu \mathrm{M})$.

\section{Hematopoietic pluripotent stem cell cultures}

The hematopoietic pluripotent stem cells derived from human blood samples support an in vitro clonogenic culture system, known as colony-forming unit assay (CFU), simulating the in vivo erythropoiesis in the bone marrow. The cell colonies of the different morphology finally obtained by this type of cultures are the CFU-E (colony-forming unit-erythroid) and the BFU-E (burst-forming unit-erythroid), which are apparent after 14-16 days of continuous culture (Fig. 2).

Peripheral blood (PBMCs) and cord blood mononuclear cells, enriched in $\mathrm{CD}_{3} 4^{+}$, were isolated with Histopaque-1077 (Sigma-Aldrich) following the vendor's protocol. Single cell common myeloid progenitors (isolated from bone marrow aspirates) were also induced for erythrocyte expansion and differentiation in the same culture conditions. In all cases, $10^{5}$ cells were cultivated in the semi-solid culture media (MethoCultt GF+ H4435, StemCell Technologies), containing the appropriate cytokine cocktail plus erythropoietin.

At day 13, culture medium was supplemented with the pharmacological factor HU (Sigma), freshly prepared, at 
Table 2 In vitro samples (III and IV)

\begin{tabular}{|c|c|c|c|c|}
\hline Sample ID & In vitro $\mathrm{Y}$-globin $(+\mathrm{HU} /-\mathrm{HU})$ & Baseline HbF (-HU) & Plateau HbF (+HU) & In vivo $\mathrm{HbF}(+\mathrm{HU}) /(-\mathrm{HU})$ \\
\hline IV CG1 & 1.75 & $x$ & $x$ & $x$ \\
\hline IV CG2 & 1.38 & $x$ & $x$ & $x$ \\
\hline IV CG3 & 1.26 & $x$ & $x$ & $x$ \\
\hline IV CG4 & 1.69 & $x$ & $x$ & $x$ \\
\hline III NR1 & 1.35 & 3.4 & 4.6 & 1.35 \\
\hline III NR2 & 1.54 & 2.5 & 2.9 & 1.16 \\
\hline III NR3 & 2.12 & 0.6 & 1 & 1.67 \\
\hline III NR4 & 1.43 & 2.1 & 2.9 & 1.38 \\
\hline III R1 & 1.09 & 6.1 & 22.6 & 3.7 \\
\hline III R2 & 3.66 & 6.7 & 16.4 & 2.5 \\
\hline III R3 & 2.31 & 10.7 & 31 & 2.89 \\
\hline III R4 & 2.56 & 9.8 & 24.5 & 2.5 \\
\hline III R5 & 1.87 & 2.7 & 15.1 & 5.6 \\
\hline IV UCB1 & 2.02 & $x$ & $x$ & $x$ \\
\hline IV UCB2 & 2.57 & $x$ & $x$ & $x$ \\
\hline IV UCB3 & 1.96 & $x$ & $x$ & $x$ \\
\hline IV UCB4 & 2.34 & $x$ & $x$ & $x$ \\
\hline IV BM1 & 5.58 & $x$ & $x$ & $x$ \\
\hline IV BM2 & 4.44 & $x$ & $x$ & $x$ \\
\hline IV BM3 & 3.25 & $x$ & $x$ & $x$ \\
\hline IV BM4 & 5.02 & $x$ & $x$ & $x$ \\
\hline
\end{tabular}

concentrations between 50 and $100 \mathrm{mM}$ for monitoring the effect of the pharmaceutical agent. In parallel, CFUs were carried under the same conditions apart from the addition of $\mathrm{HU}$. At day 16, when cells reached the BFU-E stage of differentiation, cultures were terminated. Viability of the cells was checked by trypan blue dye exclusion test. Single BFU-E colonies were randomly picked under an inverted microscope (Leica DMI), whereas the rest of the colonies (derived from the same plating) were collectively pooled and used for DNA/RNA extraction. Genetic

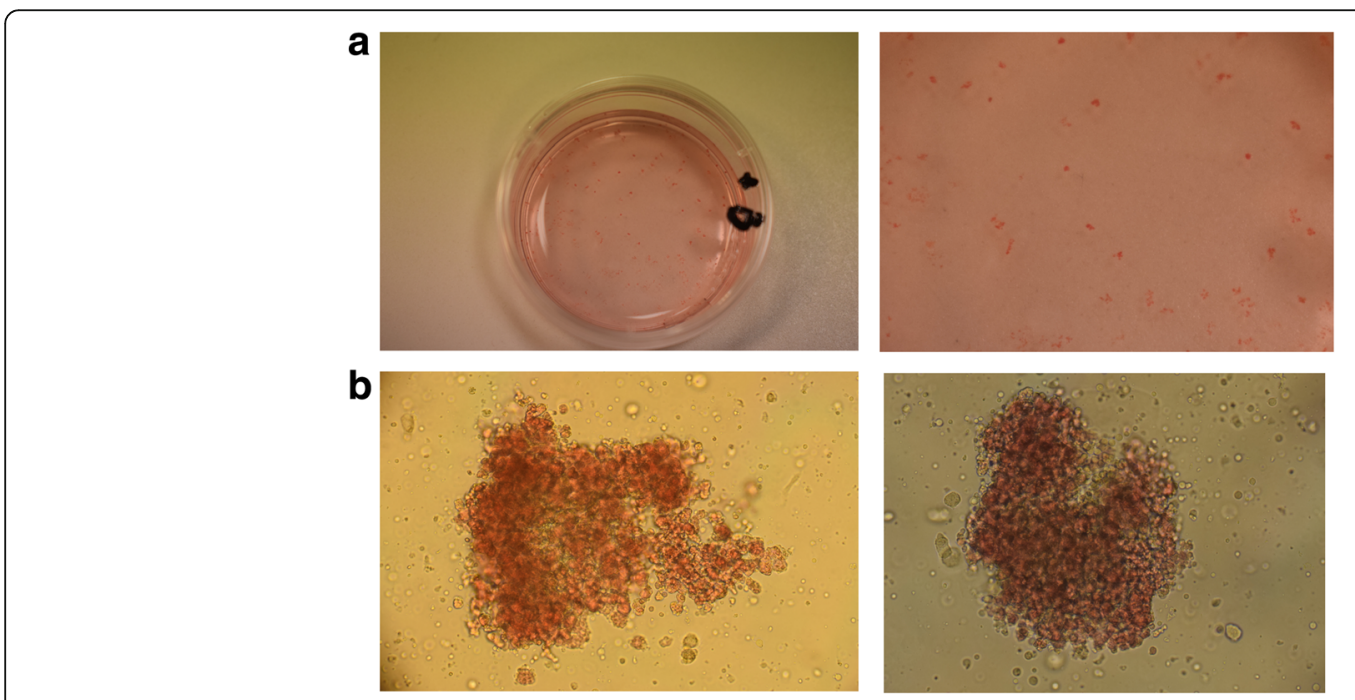

Fig. 2 BFU-E colonies derived from CFU assay. a Plate with BFU-E colonies, at day 16 (end of culture period), naturally colored red due to hemoglobin synthesis. b Two representative BFU-E colonies, observed under the inverted microscope $(\times 100)$ 
material from BFU-Es was processed to bisulphite treatment followed by pyrosequencing methylation assays and RNA to qPCR experiments.

\section{Detection of relative gene expression by RNA quantification (qRT-PCR)}

In quantitative PCRs, the amount of target cDNA (either $\gamma$-globin or LRF/ZBTB7A) was compared and normalized to the amount of GAPDH reference gene expression. cDNAs were amplified using QuantiFast SYBR Green PCR (Qiagen) and the ECO (Illumina) instrument. The target and internal reference gene were run in separate duplicate or triplicate reactions using primers reported at Table 3. $\gamma$-Globin, towards GAPDH reaction conditions, were as follows: $10 \mathrm{~s}$ at $95{ }^{\circ} \mathrm{C}, 30 \mathrm{~s}$ at $58{ }^{\circ} \mathrm{C}$, 40 cycles (Additional file 1: Figure S1), and LRF/ $Z B T B 7 A$ to GAPDH were done according to Shen et al. [31] (Fig. 5).

Gene expression in BFU-E colonies was calculated as relative expression of treated compared to untreated with $\mathrm{HU}$ colonies, using the formula $2^{(-\Delta \mathrm{Ct})}$ and normalized to the reference GAPDH gene.

\section{Methylation analysis}

The methylation status of all CpG DNA sequences was determined with the Pyrosequencing CpG assay methodology in duplicate or triplicate analysis indicating a good technical reproducibility and validation of the method. To achieve the complete conversion of the unmethylated cytosines (existing as $\mathrm{CpG}$ dinucleotides) to uraciles, bisulphite method (Qiagen) was utilized. Pyrosequencing reactions were performed with the PyroMark Q24 MDx technology (Qiagen). Methylated and unmethylated (bisulphite converted) human DNAs plus unmethylated (physiological) human DNA were used as internal controls in every round of pyrosequencing reactions. Different sequencing primers, specific for the methylation analysis of each DNA CpG sequence, were designed as well as all PCR primers sets with the PyroMark Assay Design Software, version 2.0 (Qiagen) (Table 3). Variation in methylation status of various CPG sites was detected and presented in a sequence context (Additional file 1: Figure S2, S3). Quality controls for the bisulphite conversion efficiency were introduced in every Pyrosequencing run set.

\section{Sodium bisulphite treatment modification for the single- colony $\mathrm{CpG}$ assays}

Before DNA methylation analysis, normal cytosine residues, existing as $\mathrm{CpG}$ dinucleotides, were completely converted to uracil residues while 5-methylocytosine residues remained unchanged through sodium bisulphite conversion reaction. In this study, a modified protocol for bisulphite treatment of single colonies of human erythroid progenitor cells was developed bypassing the DNA extraction step and based on the standard protocol of EpiTect Bisulphite kit (Qiagen, Hilden, Germany) for sodium bisulphite conversion of unmethylated cytosines in DNA from low-concentration solutions. In particular, for the preparation of bisulphite reactions, a single colony of each sample (of maximum $10^{6}$ cells per colony) was stored at $-80{ }^{\circ} \mathrm{C}$ for at least $2 \mathrm{~h}$ to obtain cell membrane damage. After thawing, $40 \mu \mathrm{l}$ of DNase-free water was added, mixed by vigorous pipetting, and the protocol for the low concentration solutions of DNA was followed. The eluted (treated) DNA per single colony was stored at $-20{ }^{\circ} \mathrm{C}$ until use.

\section{Statistical analysis and correlation of methylation and expression results}

Statistical analysis was performed for all data collected regarding percentage of methylation per $\mathrm{CpG}$ site and mRNA levels. Results were correlated either to the corresponding gene expression percentages or to the methylation/hypomethylation impact of the $\mathrm{CpG}$ islands of all studied genes before and after the HU treatment.

The results of the methylation analysis were presented as mean ratio of the methylation levels at $\mathrm{CpG}$ sites within gene loci of interest. Statistical analysis and boxplots were performed using SPSS software version 20. Depending on the normality tests of datasets, independent sample $t$ test or Mann-Whitney test was used to compare untreated $(-\mathrm{HU})$ single BFU-E colonies and single BFU-E colonies treated with $\mathrm{HU}(+\mathrm{HU})$ between each group. Also, the one-way ANOVA or the Kruskal-Wallis test for not normally distributed data was used for the comparison of methylation status between both untreated single BFU-E colonies and in vivo samples in all subgroups.

In all cases, $p$ values less than 0.05 were considered statistically significant.

\section{Results}

Detection and recording of $\gamma$-globin expression (in vitro) in the presence of hydroxyurea

Total RNA collected from CFU cultures was subjected to a quantitative PCR (qPCR) assay to detect $\gamma$-globin mRNA expression profile. Variation in $\gamma$-globin levels were observed in biological replicate experiments with CFU cultures from the same donor, which prompted us to refine the $\mathrm{HU}$ concentrations used in culture conditions $(50-100 \mu \mathrm{M})$. Finally, culture media was supplemented with the maximum cell-tolerated HU dose $(100 \mu \mathrm{M})$ and subsequently the effects on $\gamma$-globin gene expression were normalized, to wit $\gamma$-globin level 
Table 3 Pyrosequencing and $\mathrm{APCR}$ primer sets

\begin{tabular}{|c|c|c|c|}
\hline Gene & CpG islands & Sequence & Primers \\
\hline \multirow{8}{*}{$B C L 11 A$} & \multirow{5}{*}{ CpG 120} & 5' GTTGTTTGGAGTGGGAG 3' & Forward \\
\hline & & 5' CAAATTAAAAACTAAACCTCCAAATTAC 3' & Reverse 5'-biotin labeled \\
\hline & & 5' TIITIIITIGAGATIITAGGAGT 3' & Forward/Pyrosequencing \\
\hline & & 5'ATTACTCCCCAACACCСTCCT 3' & Reverse 5'-biotin labeled \\
\hline & & 5' TITAATTITITTAGTTAGTTG 3' & Pyrosequencing \\
\hline & \multirow{3}{*}{ CpG } & 5' GTTAGTTTGGGAGGGGGTGA 3' & Forward \\
\hline & & 5' AAACCAAATACAAACTTACCATATCC 3' & Reverse 5'-biotin labeled \\
\hline & & 5' GTTATGTGGGTTGAATG 3' & Pyrosequencing \\
\hline \multirow{4}{*}{ KLF1 } & \multirow{4}{*}{ CpG 98} & 5' GGTTAGGGGTTGGTGGTTGG 3' & Forward \\
\hline & & 5' AACCCCCCCCCCTCACCTATA 3' & Reverse 5'-biotin labeled \\
\hline & & 5' TGGGTTAGTTITGGTITA 3' & Pyrosequencing \\
\hline & & 5' GAGGATTTAGGTGTGA 3' & Pyrosequencing \\
\hline \multirow{4}{*}{ MYB } & \multirow{4}{*}{ CpG 216} & 5' GATAGTGAGTGGGAGTTGGAGGA 3' & Forward \\
\hline & & 5' CCATCAAACAAAAAACTTTAAACACT 3' & Reverse $5^{\prime}$-biotin labeled \\
\hline & & 5' GGAGGAGAGAGAGTAGAATGGGAG 3' & Pyrosequencing \\
\hline & & 5' GGTTTGTTTAGGAAAAGG 3' & Pyrosequencing \\
\hline \multirow{3}{*}{ SIN3A } & \multirow{3}{*}{ CpG 401} & 5' AGGGGGTGGTITGAAAGG 3' & Forward \\
\hline & & 5' ATATCATCCAATCCACATCCAAAA 3' & Reverse 5'-biotin labeled \\
\hline & & 5' GGGAAAAGGAAATGTATTAG 3' & Pyrosequencing \\
\hline \multirow{6}{*}{ ZBTB7A } & \multirow{6}{*}{ CpG 326} & 5' GTAGATIIITITGTGTTAAGGA 3' & Forward \\
\hline & & 5' AACAAACCCCCAACCTCTAC 3' & Reverse 5'-biotin labeled \\
\hline & & 5' GGGATTITATAGTTTATTITAAA 3' & Pyrosequencing \\
\hline & & 5' GGGTTITGGTTGTATTGTATAGTTAT 3' & Forward \\
\hline & & 5' CTCATACACTTAACCCCCAAT 3' & Reverse 5'-biotin labeled \\
\hline & & 5' GAGGGAGAGATTAGGGTA 3' & Pyrosequencing \\
\hline \multirow{3}{*}{ GATA2 } & \multirow{3}{*}{ CpG 515} & 5' ATTGTTAGGGAGGTTTAGAGTAT 3' & Forward \\
\hline & & 5' ACTCTCAAACCCCAAACTT 3' & Reverse $5^{\prime}$-biotin labeled \\
\hline & & 5' GAGAGAGTAGGGAGGGGGT 3' & Pyrosequencing \\
\hline \multirow{3}{*}{ MAP3K5 } & \multirow{3}{*}{ CpG 172} & 5' GTGGTGGAGAGGGAGAGAGTTTGTAAG 3' & Forward \\
\hline & & 5' CTAACCAACCACAACTCCAAACTACTCC 3' & Reverse 5'-biotin labeled \\
\hline & & 5' GTTITTITGGTTITITTAGA 3' & Pyrosequencing \\
\hline & qPCR primer sets & \\
\hline \multirow{2}{*}{$H B G$} & \multirow{2}{*}{-} & 5'-GAC AAG CTG CAT GTG GAT CCT-3' & Forward \\
\hline & & 5'-CCG AAA TGG ATT GCC AAA AC-3' & Reverse \\
\hline \multirow{2}{*}{ ZBTB7A } & \multirow{2}{*}{-} & 5'-CAT CTG CGA GAA GGT CAT CC-3' & Forward \\
\hline & & 5'-TGT CCT GCC TGG TGA AGC-3' & Reverse \\
\hline \multirow{2}{*}{ GAPDH } & \multirow{2}{*}{-} & 5'-CCA TGT TCG TCA TGG GTG TGA-3' & Forward \\
\hline & & 5'CAT GGA CTG TGG TCA TGA GT-3' & Reverse \\
\hline
\end{tabular}

variations between sister CFU cultures from the same donor were of no statistical significance.

BFU-E cell colonies grown at $100 \mu \mathrm{M}$ HU showed, with no exception, an increase in $\gamma$-globin calculated as relative expression. Non-responders (III NR1-4) showed a maximum of 2.1-fold increase while responders (III R1-5) a 3.66-fold, all compared to their related untreated cells (-HU) (Additional file 1: Figure S1). BFU-Es from healthy donors (IV CG1-4, UCB1-4, and BM1-4) showed a 1.35.6-fold increase in $\gamma$-globin expression. 
Correlation of $\mathrm{Y}$-globin induction (in vitro) with $\mathrm{HbF}$ levels (in vivo) upon $\mathrm{HU}$ treatment

The elevated $\gamma$-globin gene expression obtained from the ex vivo culture system (CFU) was compared to the corresponding in vivo $\mathrm{HbF}$ levels determined among patients (responders and non-responders) at relevant time points, namely, at baseline, before HU treatment, and at the plateau phase (after 5-6 months of continuous $\mathrm{HU}$ treatment). HbF levels were detected during regular preset patients' hematological tests at the Hematology Division of the Patras' University Hospital with the HPLC method. Responders (III R1-5) showed augmented $\mathrm{HbF}$ percentage, within a range of 2.55.6-fold, while non-responders (III NR1-4) exhibited an increased $\mathrm{HbF}$ percentage, always lower than 2.5 -fold difference (1.1-1.7) from baseline. Increased $\gamma$-globin gene expression (ex vivo) under the presence of $\mathrm{HU}$ was well correlated with $\mathrm{HbF}$ expression levels in patients at the plateau phase (in vivo) confirming experimental culture conditions and concentrations of HU added (Table 2).

In vivo methylation levels within $C p G$ islands of $H B B$ cluster "modifier genes" among non-responders and responders receiving $\mathrm{HU}$ treatment and control group Methylation profiles of the selected CpGs were tested in genomic material derived from peripheral mononuclear blood cells (PBMCs) of non-responders (I NR1-11) and responders (I R1-19) under long and continuous HU therapy, and of the control group (II CG1-20) (Additional file 1: Table S1). CpGs tested were CpG120 and CpG115 of BCL11A, CpG98 of KLF1, CpG216 of MYB, CpG172 of MAP3K5, CpG401 of SIN3A, CpG326 of ZBTB7A, and CpG515 of GATA2 (Table 1).

DNA from PBMCs showed an extensive heterogeneity of the methylation levels of CpG islands, and non-significant results were recorded apart from the SIN3A CpG 401. SIN3A CpG 401 was deferentially methylated between non-responders (I NR1-11) and responders (I R1-19) ( $\left.p^{*}, 0.024\right)$, with the non-responders exhibiting higher methylation rates across the entire CpG DNA sequence (data not shown). Since it is not a tissue-specific factor [32], the statistically significant differentiation of SIN $3 A$ methylation with a consequent differential expression of its protein product within PBMCs was not an unexpected result.

KLF1 CpG98, ZBTB7A CpG326, and GATA2 CpG515 did not alter significantly their methylation levels compared to all subgroups, before and after $\mathrm{HU}$ treatment. MYB CpG216, MAP3K5 CpG172, and BCL11A CpG120 had an established intrinsic methylation level of less than $10 \%$ among all groups; therefore, we concluded that we could not deliver reliable results of the $\mathrm{HU}$ effect on their methylation status.

\section{Differentiation of methylation profiles of $H B B$ cluster "modifier genes" caused by HU treatment in single BFU-E colonies derived from non-responders, responders, and control groups}

To further explore the potential epigenetic influence of $\mathrm{HU}$ and to particularize it on cells of the erythroid lineage, we isolated well-defined single BFU-E colonies (screened under an inverted microscope) [33] and determined hyper-/hypomethylation status of all CpGs in every single colony based on a slightly diverged bisulphite conversion protocol (described in the "Material and methods" section) before and after the HU treatment of the cells. Although an inter-individual character between BFU-E-matured cells within a single colony could not be excluded, uniform distribution of methylation profiles was observed in experimental replicates of individual samples and among two or three (2-3) different BFU-E colonies tested from the same donor.

Regarding the healthy control group, pluripotent hematopoietic stem cells from the peripheral (IV CG1CG4) and umbilical cord blood (IV UCB1-UCB4) as well as from bone marrow aspirations (IV BM1-BM4) were included, to explore possible fundamental epigenetic similarities with hematopoietic pluripotent stem cells derived from the patient's groups (III NR1-NR4 and III R1-R5). Responders (III R1-R5) and non-responders (III NR1-NR4) were also included in the in vitro assays, but had not entered the HU treatment regimen yet (in vitro samples, Table 2). Assortment of Rs and NRs was done long after the HU treatment initiation, based on their clinical characteristics and $\mathrm{HbF}$ induction at plateau phase. Hematopoietic pluripotent stem cells from all different tissues were expanded as described in the "Material and methods" section both without (-HU) and with $(+\mathrm{HU}) \mathrm{HU}$ addition $(100 \mu \mathrm{M})$, and at the BFU-E stage, two to three single colonies from every sample were isolated separately and subjected to methylation assay.

The methylation status of all $H B B$ cluster "modifier genes" showed mean values below $50-60 \%$ along the entire $\mathrm{CpG}$ sequences and exhibited hypomethylation in the presence of $\mathrm{HU}$ among all different groups of BFU-Es tested, which is consistent with the results from whole genome methylation assays during cell transition from early hematopoietic $\mathrm{CD} 34^{+}$to erythroid lineage committed cells [34].

MYB CpG216, MAP3K5 CpG172, and BCL11A CpG120 had the exact negligible methylation level of less than $10 \%$ before $(-\mathrm{HU})$ and after the addition of the drug $(+\mathrm{HU})$, as mentioned in the in vivo methylation reactions; therefore, statistical analysis of these areas was not performed either (Additional file 1: Figure S3). 
To the rest of the studied CpGs, the addition of $\mathrm{HU}$ $(100 \mu \mathrm{M})$ caused a general mild decrease in CpG methylation status with minor exceptions. Differential baseline methylation patterns within the $\mathrm{CpG}$ islands were obtained, before the $\mathrm{HU}$ treatment, between the differently originated descendants (BFUEs: IV CG1-4, III R1-5, III NR1-4, IV UCB1-4, and IV BM1-4). This observation suggests that $\mathrm{HU}$ action exhibits epigenetic diversity towards individual primary cell types. Statistically significant differences in the baseline methylation levels were recorded from ZBTB7A CpG326 between both BM ( $p^{*}$, $0.013)$ and UCB $\left(p^{*}, 0.016\right)$ with CG and between NR with CG $\left(p^{*}, 0.021\right)$ and NR with $\mathrm{R}\left(p^{*}, 0.019\right)$. Similar results were obtained from KLF1 CpG98 between BM and $\mathrm{UCB}\left(p^{*}, 0.038\right)$ (Fig. 3).

Statistically significant hypomethylation was obtained in the ZBTB7A $\left(p^{*}, 0.047\right)$ and GATA2 $\left(p^{*}, 0.038\right)$ CpG islands only in the NR group of patients after HU treatment (Fig. 4a). BFU-Es derived from the non-responders showed the same trend of a mild hypomethylation profile in KLF1, SIN3A, and BCL11A CpGs, but of no statistical significance (Fig. 4b) (Additional file 1: Figure S2).

The hypomethylation status of the ZBTB7A CpG326 located at the gene's proximal promoter region could lead to a possible elevated expression of LRF (leukemia/ lymphoma-related factor) and the protein product of ZBTB7A gene and could have emerged the failure of $\gamma$-globin induction above the limit of the 2.1-fold (maximum observed $\gamma$-globin relative expression), on account of the erythropoietic cells' exposure to the HU agent among non-responders. This observation led us to trace
LRF/ZBTB7A expression levels among responders and non-responders.

\section{Detection and recording of $L R F / Z B T B 7 A$ mRNA levels}

Specific primers to detect the LRF mRNA were designed (Table 3) and subjected to qPCR to quantitate its expression profile before and after the HU addition to cultivated cells. Total RNA for qPCR experiments was extracted from 30 to 50 characterized BFU-E colonies for each sample, to ensure that the LRF/ZBTB7A expression levels represent cells of the erythroid lineage and are consistent to similar methylation results obtained from single BFU-E colonies. LRF expression was calculated as previously described "Materials and methods" section). Relative LRF expression was elevated only in NR group (1.1 to1.4-fold increase) in the presence of $\mathrm{HU}$, which was in consistency with the hypomethylation results obtained in ZBTB7A CpG326 among the same group (NRs) (Fig. 5a, b). Similar studies delineate the expression of LRF/ZBTB7A at a more mature stage of red cell differentiation, after the proerythroblast stage [35]; hence, its expression at BFU-E colonies is at a minimum detectable level and only upon the simultaneous treatment of cells with the HU.

\section{Discussion}

The fine regulation of the $H B B$ cluster "modifier genes" caused by their natural epigenetic variations on DNA methylation profile and/or by HU medication widely used to treat $\beta$-hemoglobinopathies has been the target of investigation in the present study. CpG islands

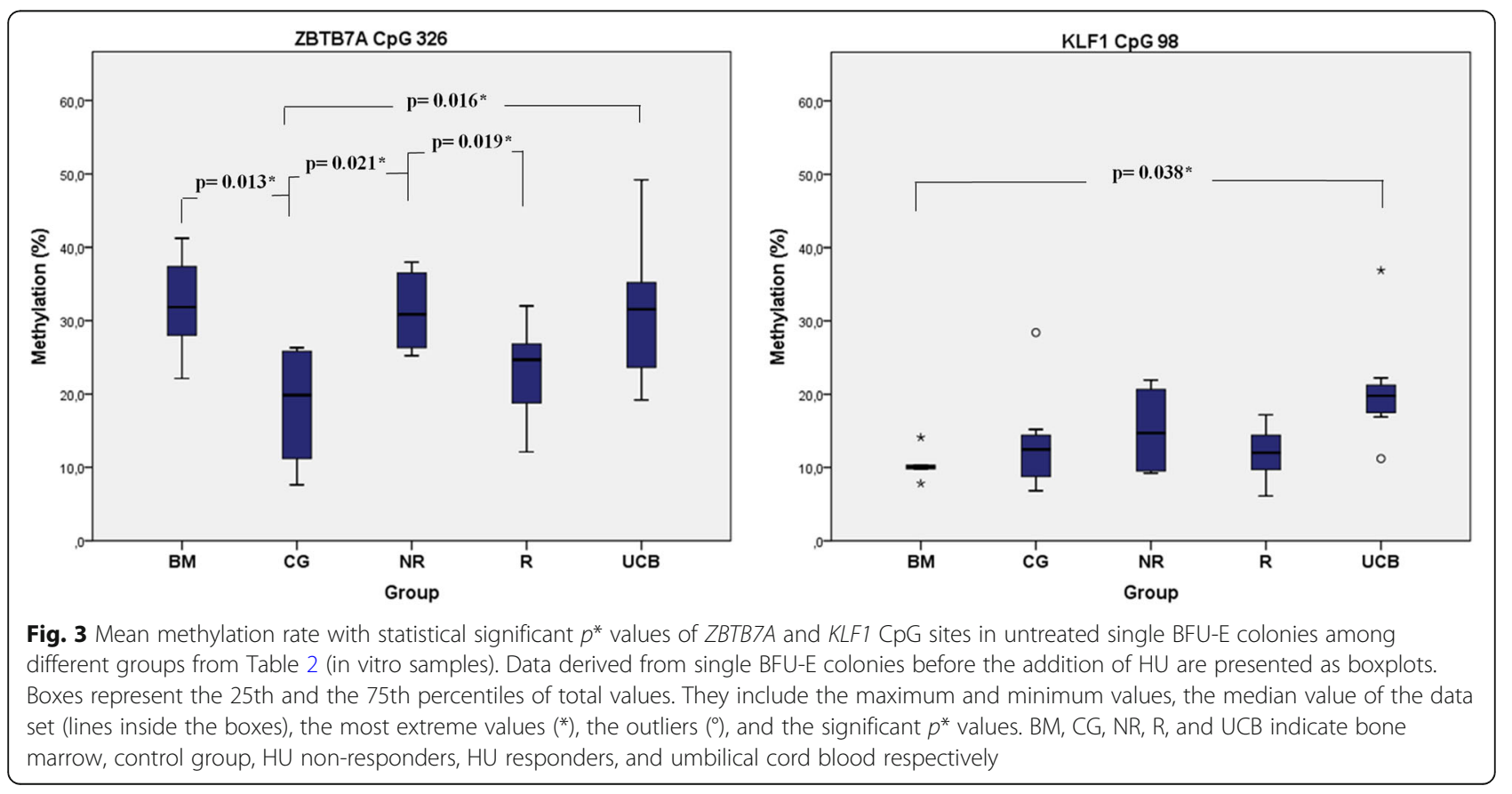



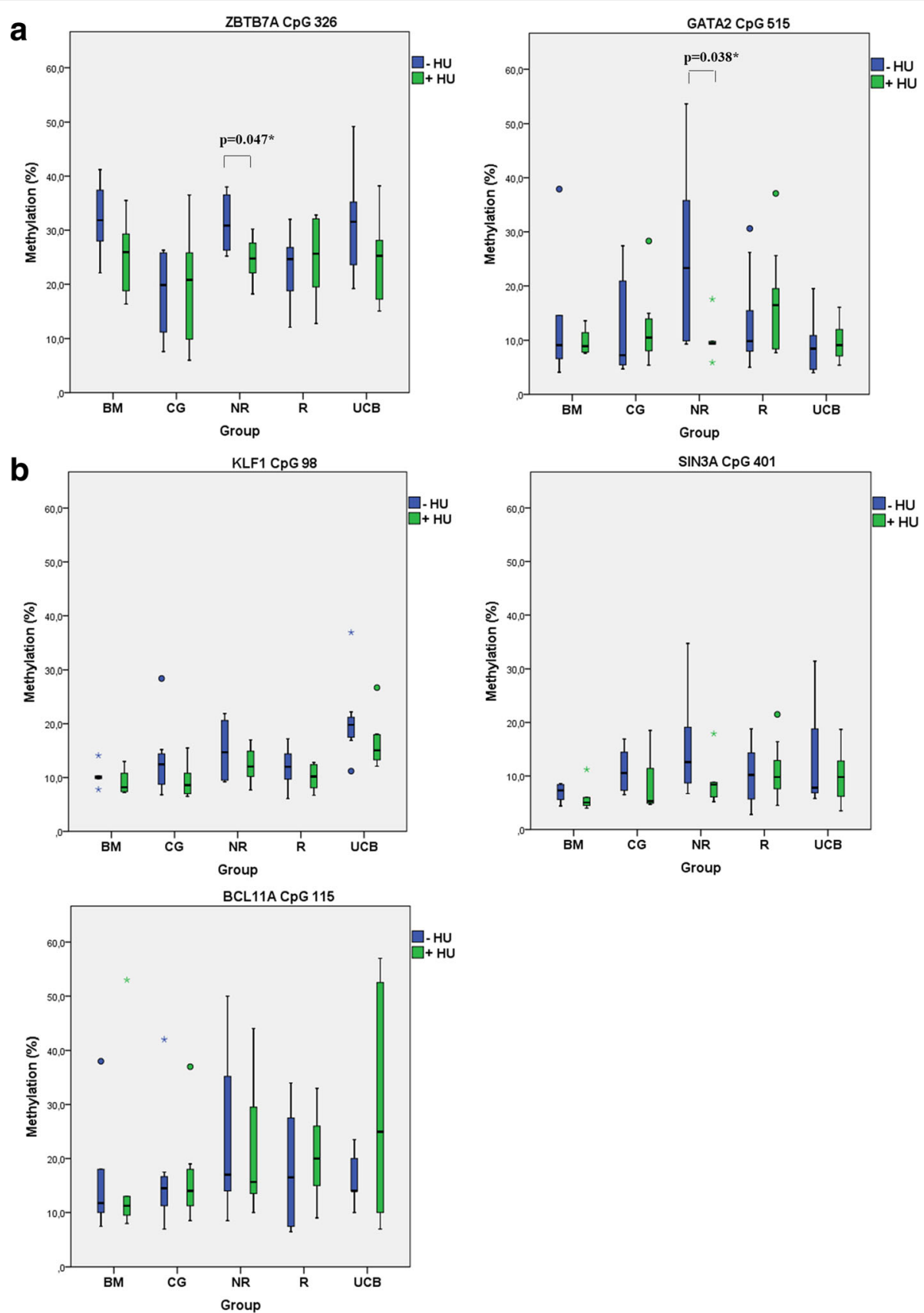

Fig. 4 Mean methylation rate of CpG sites in single BFU-E colonies before and after HU treatment among all in vitro groups of samples (Table 2). a ZBTB7A CpG 326 and GATA2 CpG 515 showed a significant hypomethylation profile in non-responders (NRs). b SIN3A CpG 401, KLF1 CpG 98, and BCL11A CpG 115 showed hypomethylation trend in NRs, though not of statistical significance. Data are presented as boxplots. Boxes represent the 25th and the 75th percentiles of total values. They include the maximum and minimum values, the median value of the data set (lines inside the boxes), the most extreme values $\left({ }^{*}\right)$, the outliers $\left({ }^{\circ}\right)$, and the significant $p^{*}$ values recorded. BM, CG, NR, R, and UCB indicate BFU-Es derived from bone marrow, control group, $\mathrm{HU}$ non-responders, $\mathrm{HU}$ responders, and umbilical cord blood respectively

included in the study were the $B C L 11 A, K L F 1, M Y B$, $M A P 3 K 5$, SIN3A, ZBTB7A, and GATA2, which are known to influence the natural developmental switch in hemoglobin expression, from fetal to adult. Nuclear factors and their genetic variations have long been investigated, but whether and to what extent they cooperate with epigenetic signals in fetal globin repression/induction is not yet fully understood.

The CpG sites selected for the present study bared factors involved in chromatin remodeling, such as the CCCT C-binding factor, known as CTCF and the leukemia/lymphoma-related factor (LRF/ZBTB7A). CTCF is a chromatin 


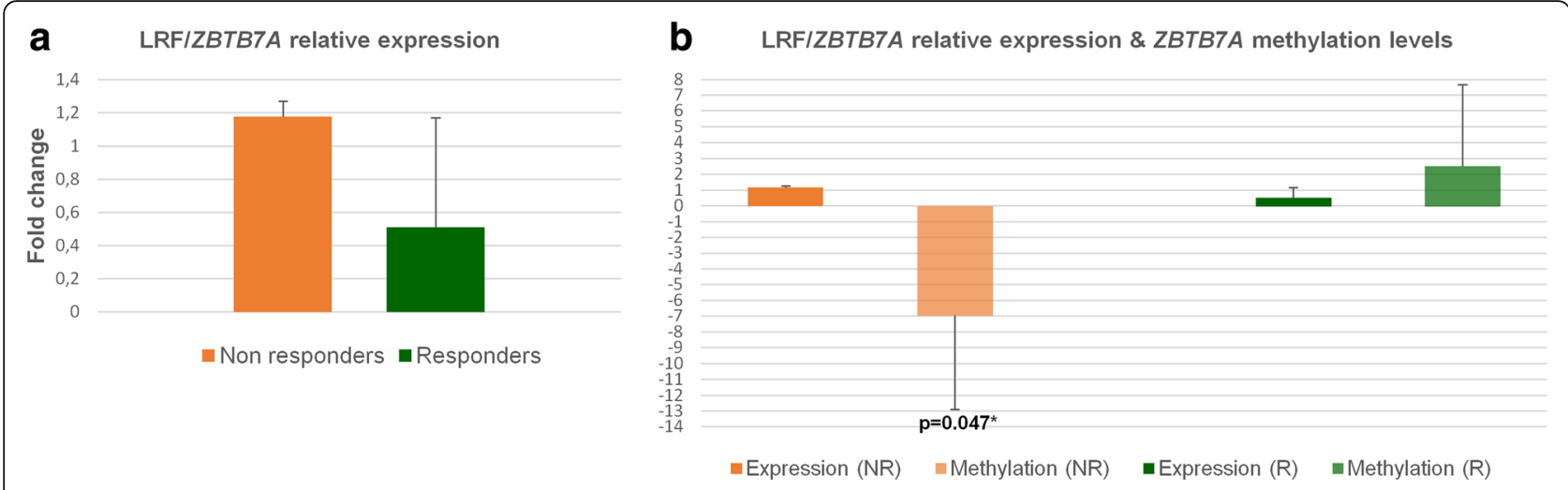

Fig. 5 Relative expression of $L R F / Z B T B 7 A$ and statistical correlations between gene's methylation and expression. a Relative expression of LRF/ ZBTB7A in BFU-E colonies of responders and non-responders (III R1-5, III NR1-4) after HU treatment. b Correlation between methylation and gene expression results in responders and non-responders (III R1-5, III NR1-4). Hypomethylation results in ZBTB7A CpG 326 were in line with the higher expression of ZBTB7A observed in non-responders. Opposite results were detected in the responders' group

structural factor that plays a key role in gene expression through the activation or repression of gene promotes, the insulation of enhancers, and the regulation of distant chromatin interactions [36]. Binding of CTCF on DNA can be altered by DNA methylation. Especially, when CTCF-binding sites contain CpG dinucleotides, binding could be methylation specific, suggesting a role for CTCF in epigenetic regulatory mechanisms [37]. Our findings in respect to the methylation repertory of the $H B B$ cluster "modifier genes" within the CpG regions encompassing CTCF-binding sites showed that it was normally distributed along the $\mathrm{CpG}$ island. These results indicated that the CTCF factor did not preserve any insulating function (at least for the genes studied) that could prevent the hypo- or hyper-methylation spreading across the specific $\mathrm{CpG}$ genome sequences, in the presence of $\mathrm{HU}$.

The LRF/ZBTB7A is a member of the POK (POZ/BTB and Krüppel) protein family, which binds to CG-rich regions and recruits histone deacetylases to gene promoters leading to a closed chromatin conformation that prevents transcription [38]. The bioinformatics analysis showed that recognition binding sites for CTCF and $Z B T B 7 A$ factors were settled at contiguous DNA sequences, while $Z B T B 7 A$-binding sites were apparent in all CpG areas selected for this study (Fig. 1). LRF/ZBTB7A factor has been characterized as an $\mathrm{HbF}$ repressor that acts independently from the known fetal globin repressor $B C L 11 A$, by recruitment of the NuRD complex [39, 40]. Another study has uncovered the combined action of $K L F 1$ with $Z B T B 7 A$ to depress $\mathrm{HbF}$ [41].

Results from the in vitro methylation assays performed in this study clearly showed a hypomethylating trend in non-responders (III NR in Fig. 4) in the presence of $\mathrm{HU}$, which reached a statistical significance for the $Z B T B 7 A$ $\left(-\mathrm{HU} /+\mathrm{HU}, p^{*}, 0.047\right)$ and the GATA2 $\left(-\mathrm{HU} /+\mathrm{HU}, p^{*}\right.$,
0.038) CpGs. Parallel gene expression experiments with RNA isolated from BFU-Es of the same cultures allowed us to directly correlate changes in methylation to gene expression. Hypomethylation of the ZBTB7A CpG326 was associated with higher levels of LRF/ZBTB7A expression in non-responders (III NR), up to 1.4-fold (Fig. 5). Hypomethylation of GATA2 CpG515 potentially enhances the GATA2 protein expression too, but levels of GATA2 mRNA were not targeted in this study. The GATA2 high expression was considered assured as premature erythroid cells (and BFU-Es) are known to express higher levels of GATA2, which in later stages of maturation switches to GATA1 [28, 42].

The HU hypomethylation effect was also visible in KLF1 CpG98, SIN3A CpG401, and BCL11A CpG115, but not at significant rates, whereas MYB CpG216, MAP3K5 CpG172, and BCL11A CpG120 were methylated at nugatory values before and after $\mathrm{HU}$. The detected minor changes in their methylation profiles were likely to be borderline, and thus, statistical analysis of these areas was not performed. Furthermore, the non-responder group of patients (III NR) had an established baseline higher methylation profile in CpG326 of ZBTB7A, in the absence of $\mathrm{HU}$, compared to responders (III R) $\left(p^{*}, 0.019\right)$ and healthy donors (IV CG) $\left(p^{*}, 0.021\right)$ (Fig. 3), suggesting an underlying epigenetic mechanism of $\mathrm{HU}$ action by the methylation modulation of the $Z B T B 7 A$, leading to an amplitude modulation of its expression. The LRF encoded by the ZBTB7A gene preferentially binds methylated CpGs and acts as a $\gamma$-globin repressor [39]. This is in accordance with our results derived from the HU non-responders. Probably, their higher baseline methylation status along the $H B B$ "modifier gene loci" favors the LRF binding, leading to a hardly irreversible suppression of the $\mathrm{HbF}$ production even under the HU influence. 
Additionally, there were statistically significant differences in the CpG326 of ZBTB7A among IV CG and IV $\mathrm{UCB}\left(p^{*}, 0.016\right)$ and IV CG and IV BM $\left(p^{*}, 0.013\right)$. Evidence from human systems indicates that pluripotent hematopoietic stem cells exhibit an epigenetic memory, related to their donor cell type of origin [43], and our results support these observations.

Results of the present study indicate that HU resets the methylation status and eventually the basal program of expression for several factors and definitely to loci unlinked to the $H B B$ cluster. The HU non-responders demonstrated an extra barrier of epigenetic regulation for the $\gamma$-globin reactivation. Even though HU provoked a similar terminal hypomethylation status to both the HU non-responders and $\mathrm{HU}$ responders, (Fig. 4a), the $\gamma$-globin expression was not ultimately prevailed in the HU non-responders. The most likely explanation is that expression of the $\beta$ - and $\gamma$-globin genes is still inherently unstable at the BFU-E stage and that micro-environmental conditions persisting during the erythroid differentiation determine whether $\beta$ or $\gamma$-globin expression will be favored.

Previous attempts to detect DNA methylation changes in $\mathrm{CpG}$ sequences lying at neighboring areas to the $\gamma^{G}$-globin promoter have not achieved any informative insights [44]. Also, the $\mathrm{HU}$ epigenetic effect is manifested only in $H B B$ modifier factors, derived from cells of the erythroid lineage, which was apparent from our study. A considerable heterogeneity on the epigenetic effect detected at the in vivo samples was attributed to the different origins and the subsistence of mixed cell populations within PBMCs. On the contrary, BFUEs (in vitro samples) consist of a cell population obtained from cell/ tissue culture systems, uniformly differentiated towards the erythropoietic lineage, albeit PBMCs isolated from blood samples included a mixture of all mononuclear blood cells, which although they were exposed to the daily dose of $\mathrm{HU}$, they seem not to have responded homogeneously. The methylation profile of all CpG islands gave significant results only when the research focused on well-characterized single erythroid colonies (BFU-Es), with the unique exception of the SIN3A CpG 401 , which is not an erythroid tissue-specific factor. The SIN3A protein consists of multiple protein interaction domains and contacts a variety of binding partners to perform its biological function, whereas it is considered to co-operate with histone-modifying complexes exhibiting a global transcription regulatory property [32]. Hence, SIN3A was differentially methylated $\left(p^{*}, 0.024\right)$ between the in vivo samples (PBMCs) of HU non-responders and $\mathrm{HU}$ responders.

The role of $Z B T B 7 A$ as an $\mathrm{HbF}$ repressor is fully supported by our data, due to its broad existence as a binding factor to all CpG islands selected and analyzed in this study, its significant hypomethylation, and the elevated levels (although modest) of LRF/ZBTB7A expression in non-responders treated with $\mathrm{HU}$ (Fig. 5). On the contrary, the baseline hypomethylated ZBTB7Abinding sites in the $\mathrm{HU}$ responder group of patients either do not show preference for the LRF binding or LRF is produced at adverse levels unable to force the $\gamma$-globin repression.

The present epigenetic analysis of the $H B B$ cluster "modifier genes" provides some valuable information related to the heterogeneous response to $\mathrm{HU}$, in an effort to predict patients' response to treatment. We evaluated the $\mathrm{HU}$ potential as a hypomethylating agent although HU has not been previously associated with epigenetic responses, other than enhancing the expression of specific miRNAs [45-47]. Several miRNAs have been highlighted as epigenetic regulators of erythroid differentiation that influence $\mathrm{HbF}$ production (miR-26b, miR-151-3p, miR210) upon HU treatment. In contrast to fixed genome sequence, epigenetic patterns are plastic; thus, correcting aberrant, disease-causing epigenetic marks holds considerable therapeutic promise.

\section{Conclusions and future perspectives}

A drawback to current HU treatment for the SCA and $\mathrm{SCA} / \beta$-thal patients is its non-specific effects. Our pharmacoepigenomic study reveals the epigenetic pharmacological activity of $\mathrm{HU}$ distinguishes the different epigenetic regulatory nuclear mechanisms acting among $\mathrm{HU}$ responders and $\mathrm{HU}$ non-responders and contributes to the development of a clinical algorithm for improved prediction of the patients' response to HU treatment.

The ZBTB7A appears as an emerging epigenetic regulator of the $\mathrm{HbF}$ induction bypassing the already known repressors of $\gamma$-globin expression. ZBTB7A possibly exerts its repressing function to the $\gamma$-globin gene through a chromatin remodeling pathway, which is supported by the broad existence of its multiple recognition binding sites close to all $H B B$ cluster "modifier loci" tested. The $Z B T B 7 A / L R F$ epigenetically induced binding to preconfigured $H B B$ cluster "modifier genes" promoters should also be investigated, to uncover the vital changes to promoter accessibility and subsequent motivations for gene activation or repression.

Moreover, the methodology of the single-colony (BFU-E) DNA methylation analysis, developed by our lab, seems to be mostly appropriate and informative for the specific cell epigenetic responses towards the $\mathrm{HbF}$ re-induction pathway during treatment with HU. In addition to our results, it would be very interesting to investigate the epigenetic marks of reprogrammed erythroid progenitors further, under the influence of $\mathrm{HU}$ or other $\mathrm{HbF}$ inductive agents in immature proerythroblasts and other subpopulations of the hematopoietic cell lineage. Critical questions such as whether $\mathrm{CpG}$ 
islands of different tissues are uniformly targeted by the epigenetic machinery components or some are "safeguarded" by nuclear factors and remain unaffected need further insight.

Contemporary medication focused on the $H B B$ locus-specific modifiers, used in conjunction with epigenetic biomarkers of response, as ZBTB7A CpG326 and GATA2 CpG515, highlighted in this study, will enable truly precision interventions.

\section{Additional file}

Additional file 1: Table S1. Hematological data of HU responders (R) and $\mathrm{HU}$ non-responders (NR) used as in vivo samples. Figure S1 In vivo HbF levels and $\gamma$-globin expression in vitro before and after HU treatment. (a) III NR2 and (b) III NR4 patients (Table 2) at baseline of HbF expression before HU treatment (c) III NR2, (d)III NR4 and (e) III R5 patients at the plateau phase, with maximum detected $\mathrm{HbF}$ expression levels. Arrows show the $\mathrm{HbF}$ curve. $(f) \gamma$-globin gene expression in BFU-E colonies calculated as relative expression of treated compared to untreated with $\mathrm{HU}$ colonies, using the formula $2^{(-\Delta C t)}$ and normalized to the reference GAPDH gene. Figure S2 DNA methylation levels estimated by the pyrosequencing CpG assay. Typical pyrograms displaying DNA methylation analyses before and after cells' treatment with HU of: (a) ZBTB7A CpG 326, (b) GATA2 CpG 515, (c) KLF1 CpG 98, (d) SIN3A CpG 401, (e) BCL11A CpG 115. Figure S3 DNA methylation levels less than $10 \%$ either with or without the addition of $\mathrm{HU}$, estimated using the pyrosequencing $\mathrm{CpG}$ assay. Typical pyrograms displaying DNA methylation levels of (a) BCL11A CpG 120, and (b) MYB CpG 216. (ZIP $3179 \mathrm{~kb})$

\section{Abbreviations}

BFU-E: Burst-forming unit-erythroid; BM: Bone marrow; CFU: Colony-forming unit assay; CFU-E: Colony-forming unit-erythroid; CG: Control group; HbF: Fetal hemoglobin; HU: Hydroxyurea; NR: Non-responders; PBMCs: Peripheral blood mononuclear cells; R: Responders; SCA: Sickle cell anemia; UCB: Umbilical cord blood

\section{Acknowledgements}

The authors wish to thank all patients and donors for providing samples for the completion of this research. We would like to thank Vassiliki Pesli, who performed all venipunctures to patients and controls for blood collection, and Constantina Argyropoulou, who performed the HPLC for HbF estimations. We also acknowledge George Georgis from HOU for providing technical assistance with the figures.

\section{Funding}

This research was financially supported by PENER_EAP_2016 grant of the Hellenic Open University.

\section{Availability of data and materials}

The datasets supporting the conclusions of this article are included within the article and its Additional file 1.

\section{Authors' contributions}

VC designed and performed all methylation assays and was responsible for the CFU cultures. EFS designed and performed qPCRs and was also responsible for the CFU cultures. AKS, ArSy, EV, and PC were responsible for monitoring of the patients, collection of their hematological data, and revision of the manuscript. GM did all the bioinformatics analysis. VF performed the statistical analysis. GPP, AP, and ArSg designed the study, elaborated the data, and reviewed the manuscript. ArSg supervised the whole research project and wrote the manuscript. All authors read and approved the final manuscript.

\section{Ethics approval and consent to participate}

The whole process of sample collection (peripheral blood and bone marrow aspirations) was carried in accordance to ethical guidelines and under the supervision of the Thalassemia \& Hemoglobinopathies Unit, Division of Hematology of the Patras' University Hospital. The study has been approved by the Patras' University Hospital Ethical and Scientific Committee, and a written informed consent to participation from all patients and healthy donors was obtained. Fresh umbilical cord blood samples were collected from the Hellenic Cord Blood Bank (HCBB) of the Biomedical Research Foundation Academy of Athens from healthy donors after their positive response to donate a portion of the sample $(2-3 \mathrm{ml})$ for scientific research purposes.

\section{Consent for publication}

Not applicable.

\section{Competing interests}

The authors declare that they have no competing interests.

\section{Publisher's Note}

Springer Nature remains neutral with regard to jurisdictional claims in published maps and institutional affiliations.

\section{Author details}

${ }^{1}$ School of Science and Technology, Biology Laboratory, Hellenic Open University, Patras, Greece. ${ }^{2}$ Faculty of Medicine, Biology Laboratory, University of Ioannina, loannina, Greece. ${ }^{3}$ Thalassemia and Hemoglobinopathies Unit, Hematology Division, Department of Internal Medicine, General University Hospital of Patras, Patras, Greece. ${ }^{4}$ School of Science and Technology, Digital Systems and Media Computing Laboratory, Hellenic Open University, Patras, Greece. ${ }^{5}$ Medical School, Hematology Division, Department of Internal Medicine, University of Patras, Patras, Greece. ${ }^{6}$ Thalassemia Unit, "Hippokrateio" General Hospital of Thessaloniki, Thessaloniki, Greece. ${ }^{7}$ Thalassemia and Sickle Cell Unit, AHEPA University General Hospital of Thessaloniki, Thessaloniki, Greece. ${ }^{8}$ School of Health Sciences, Department of Pharmacy, Laboratory of Pharmacogenomics and Individualized Therapy, University of Patras, Patras, Greece. ${ }^{9}$ Medical Faculty, Laboratory of General Biology, University of Patras, Patras, Greece.

Received: 1 August 2018 Accepted: 11 September 2018 Published online: 01 October 2018

\section{References}

1. Taher AVE, Musallam K, Cappellini MD, Viprakasit V. Guidelines for the management of non transfusion dependent thalassaemia (NTDT). Nicosia Cyprus: Thalassaemia International Federation; 2013.

2. Giannopoulou E, Bartsakoulia M, Tafrali C, Kourakli A, Poulas K, Stavrou EF, et al. A single nucleotide polymorphism in the HBBP1 gene in the human beta-globin locus is associated with a mild beta-thalassemia disease phenotype. Hemoglobin. 2012:36(5):433-45. https://doi.org/10.3109/ 03630269.2012.717515

3. Lessard S, Beaudoin M, Benkirane K, Lettre G. Comparison of DNA methylation profiles in human fetal and adult red blood cell progenitors. Genome Med. 2015;7(1):1. https://doi.org/10.1186/s13073-014-0122-2.

4. Lavelle $D E$. The molecular mechanism of fetal hemoglobin reactivation. Semin Hematol. 2004;41(4 Suppl 6):3-10.

5. Gravia A, Chondrou V, Sgourou A, Papantoni I, Borg J, Katsila T, et al. Individualizing fetal hemoglobin augmenting therapy for beta-type hemoglobinopathies patients. Pharmacogenomics. 2014;15(10):1355-64. https://doi.org/10.2217/pgs.14.101.

6. Kolliopoulou A, Stratopoulos A, Siamoglou S, Sgourou A, Ali BR, Papachatzopoulou A, et al. Key pharmacogenomic considerations for sickle cell disease patients. OMICS. 2017;21(6):314-22. https://doi.org/10.1089/omi. 2017.0058.

7. Platt OS, Orkin SH, Dover G, Beardsley GP, Miller B, Nathan DG. Hydroxyurea enhances fetal hemoglobin production in sickle cell anemia. J Clin Invest. 1984;74(2):652-6. https://doi.org/10.1172/JCl111464.

8. Mabaera R, West RJ, Conine SJ, Macari ER, Boyd CD, Engman CA, et al. A cell stress signaling model of fetal hemoglobin induction: what doesn't kill red blood cells may make them stronger. Exp Hematol. 2008;36(9):1057-72. https://doi.org/10.1016/j.exphem.2008.06.014.

9. Musallam KM, Taher AT, Cappellini MD, Sankaran VG. Clinical experience with fetal hemoglobin induction therapy in patients with beta-thalassemia. 
Blood. 2013;121(12):2199-212; quiz 372. https://doi.org/10.1182/blood-201210-408021.

10. Rigano P, Pecoraro A, Calzolari R, Troia A, Acuto S, Renda D, et al. Desensitization to hydroxycarbamide following long-term treatment of thalassaemia intermedia as observed in vivo and in primary erythroid cultures from treated patients. Br J Haematol. 2010;151(5):509-15. https://doi.org/10.1111/j.1365-2141.2010.08397.x.

11. Mancuso A, Maggio A, Renda D, Di Marzo R, Rigano P. Treatment with hydroxycarbamide for intermedia thalassaemia: decrease of efficacy in some patients during long-term follow up. Br J Haematol. 2006;133(1):105-6. https://doi.org/10.1111/j.1365-2141.2006.06002.x.

12. Gluckman PD, Hanson MA, Buklijas T, Low FM, Beedle AS. Epigenetic mechanisms that underpin metabolic and cardiovascular diseases. Nat Rev Endocrinol. 2009;5(7):401-8. https://doi.org/10.1038/nrendo.2009.102.

13. Tang J, Xiong Y, Zhou HH, Chen XP. DNA methylation and personalized medicine. J Clin Pharm Ther. 2014;39(6):621-7. https://doi.org/10.1111/jcpt. 12206.

14. Bird A. DNA methylation patterns and epigenetic memory. Genes Dev. 2002;16(1):6-21. https://doi.org/10.1101/gad.947102.

15. Sheehan VA, Luo Z, Flanagan JM, Howard TA, Thompson BW, Wang WC, et al. Genetic modifiers of sickle cell anemia in the BABY HUG cohort: influence on laboratory and clinical phenotypes. Am J Hematol. 2013;88(7): 571-6. https://doi.org/10.1002/ajh.23457.

16. Liu P, Keller JR, Ortiz M, Tessarollo L, Rachel RA, Nakamura T, et al. Bcl11a is essential for normal lymphoid development. Nat Immunol. 2003;4(6):525-32. https://doi.org/10.1038/ni925.

17. Tafrali C, Paizi A, Borg J, Radmilovic M, Bartsakoulia M, Giannopoulou E, et al. Genomic variation in the MAP3K5 gene is associated with beta-thalassemia disease severity and hydroxyurea treatment efficacy. Pharmacogenomics. 2013;14(5):469-83. https://doi.org/10.2217/pgs.13.31.

18. Graviał A, Chondrouł V, Kolliopoulou A, Kourakli A, John A, Symeonidis A, Ali BR, Sgourou A, Papachatzopoulou A, Katsila T, Patrinos GP. "Correlation of SIN3A genomic variants with $\beta$-hemoglobinopathies disease severity and hydroxyurea treatment efficacy". Pharmacogenomics. 2016;17(16). https:// doi.org/10.2217/pgs-2016-0076, https://www.ncbi.nlm.nih.gov/pubmed/ 27767389.

19. Uda M, Galanello R, Sanna S, Lettre G, Sankaran VG, Chen W, et al. Genomewide association study shows BCL11A associated with persistent fetal hemoglobin and amelioration of the phenotype of beta-thalassemia. Proc Natl Acad Sci U S A. 2008;105(5):1620-5. https://doi.org/10.1073/pnas. 0711566105

20. Zhou D, Liu K, Sun CW, Pawlik KM, Townes TM. KLF1 regulates BCL11A expression and gamma- to beta-globin gene switching. Nat Genet. 2010; 42(9):742-4. https://doi.org/10.1038/ng.637.

21. Zhang JS, Moncrieffe MC, Kaczynski J, Ellenrieder V, Prendergast FG, Urrutia R. A conserved alpha-helical motif mediates the interaction of Sp1-like transcriptional repressors with the corepressor mSin3A. Mol Cell Biol. 2001; 21(15):5041-9. https://doi.org/10.1128/MCB.21.15.5041-5049.2001.

22. Wahlberg K, Jiang J, Rooks H, Jawaid K, Matsuda F, Yamaguchi M, et al. The HBS1L-MYB intergenic interval associated with elevated HbF levels shows characteristics of a distal regulatory region in erythroid cells. Blood. 2009; 114(6):1254-62. https://doi.org/10.1182/blood-2009-03-210146.

23. Kawata H, Yamada K, Shou Z, Mizutani T, Yazawa T, Yoshino M, et al. Zincfingers and homeoboxes (ZHX) 2, a novel member of the ZHX family, functions as a transcriptional repressor. Biochem J. 2003;373(Pt 3):747-57. https://doi.org/10.1042/BJ20030171.

24. Sankaran VG, XU J, Ragoczy T, Ippolito GC, Walkley CR, Maika SD, et al. Developmental and species-divergent globin switching are driven by BCL11A. Nature. 2009;460(7259):1093-7. https://doi.org/10.1038/nature08243.

25. Dumitriu BB, Dy P, Huang P, Quayum Y, Jensen N, Lefebvre J. Sox6 is necessary for efficient erythropoiesis in adult mice under physiological and anemia-induced stress conditions. PLoS One. 2010;5(8):e12088. https://doi. org/10.1371/journal.pone.0012088.

26. Borg J, Papadopoulos P, Georgitsi M, Gutierrez L, Grech G, Fanis P, et al. Haploinsufficiency for the erythroid transcription factor KLF1 causes hereditary persistence of fetal hemoglobin. Nat Genet. 2010;42(9):801-5. https://doi.org/10. 1038/ng.630.

27. Borg J, Patrinos GP, Felice AE, Philipsen S. Erythroid phenotypes associated with KLF1 mutations. Haematologica. 2011;96(5):635-8. https://doi.org/10. 3324/haematol.2011.043265.
28. Suzuki M, Yamamoto M, Engel JD. Fetal globin gene repressors as drug targets for molecular therapies to treat the beta-globinopathies. Mol Cell Biol. 2014;34(19):3560-9. https://doi.org/10.1128/MCB.00714-14.

29. Kent WJ, Sugnet CW, Furey TS, Roskin KM, Pringle TH, Zahler AM, et al. The human genome browser at UCSC. Genome Res. 2002;12(6):996-1006. https://doi.org/10.1101/gr.229102.

30. Consortium. EP. An integrated encyclopedia of DNA elements in the human genome. Nature. 2012;489(7414):57-74. https://doi.org/10.1038/nature11247.

31. Shen Y, Cao R, Liu W, Zhou Y, Wu Y, Tan J, et al. Negative feedback loop between ZBTB7A and TGF-beta in breast cancer. Oncol Lett. 2017;14(2): 1403-10. https://doi.org/10.3892/ol.2017.6291.

32. Chaubal A, Pile LA. Same agent, different messages: insight into transcriptional regulation by SIN3 isoforms. Epigenetics Chromatin. 2018; 11(1):17. https://doi.org/10.1186/s13072-018-0188-y.

33. Nissen-Druey CT, A. Meyer-Monard, S. Human hematopoietic colonies in health and disease.; 2005.

34. Yu Y, Mo Y, Ebenezer D, Bhattacharyya S, Liu H, Sundaravel S, et al. High resolution methylome analysis reveals widespread functional hypomethylation during adult human erythropoiesis. J Biol Chem. 2013: 288(13):8805-14. https://doi.org/10.1074/jbc.M112.423756.

35. Maeda T. Regulation of hematopoietic development by ZBTB transcription factors. Int J Hematol. 2016;104(3):310-23. https://doi.org/10.1007/s12185016-2035-x.

36. Kim S, Yu NK, Kaang BK. CTCF as a multifunctional protein in genome regulation and gene expression. Exp Mol Med. 2015;47:e166. https://doi.org/ 10.1038/emm.2015.33.

37. Filippova GN. Genetics and epigenetics of the multifunctional protein CTCF. Curr Top Dev Biol. 2008;80:337-60. https://doi.org/10.1016/S00702153(07)80009-3.

38. Lunardi A, Guarnerio J, Wang G, Maeda T, Pandolfi PP. Role of LRF/Pokemon in lineage fate decisions. Blood. 2013;121(15):2845-53. https://doi.org/10. 1182/blood-2012-11-292037.

39. Masuda T, Wang X, Maeda M, Canver MC, Sher F, Funnell AP, et al. Transcription factors $L R F$ and BCL11A independently repress expression of fetal hemoglobin. Science. 2016;351(6270):285-9. https://doi.org/10.1126/ science.aad3312.

40. Vinjamur DS, Bauer DE, Orkin SH. Recent progress in understanding and manipulating haemoglobin switching for the haemoglobinopathies. $\mathrm{Br} J$ Haematol. 2018;180(5):630-43. https://doi.org/10.1111/bjh.15038.

41. Norton LJ, APW F, Burdach J, Wienert B, Kurita R, Nakamura Y, et al. KLF1 directly activates expression of the novel fetal globin repressor ZBTB7A/LRF in erythroid cells. Blood Adv. 2017;1(11):685-92. https://doi.org/10.1182/ bloodadvances.2016002303.

42. Anguita E, Hughes J, Heyworth C, Blobel GA, Wood WG, Higgs DR. Globin gene activation during haemopoiesis is driven by protein complexes nucleated by GATA-1 and GATA-2. EMBO J. 2004;23(14):2841-52. https://doi. org/10.1038/sj.emboj.7600274.

43. Kim K, Zhao R, Doi A, Ng K, Unternaehrer J, Cahan P, et al. Donor cell type can influence the epigenome and differentiation potential of human induced pluripotent stem cells. Nat Biotechnol. 2011;29(12):1117-9. https:// doi.org/10.1038/nbt.2052.

44. Walker AL, Steward S, Howard TA, Mortier N, Smeltzer M, Wang YD, et al. Epigenetic and molecular profiles of erythroid cells after hydroxyurea treatment in sickle cell anemia. Blood. 2011;1 18(20):5664-70. https://doi.org/ 10.1182/blood-2011-07-368746.

45. Bianchi N, Zuccato C, Lampronti I, Borgatti M, Gambari R. Expression of miR210 during erythroid differentiation and induction of gamma-globin gene expression. BMB Rep. 2009;42(8):493-9.

46. Svasti S, Masaki S, Penglong T, Abe Y, Winichagoon P, Fucharoen $S$, et al. Expression of microRNA-451 in normal and thalassemic erythropoiesis. Ann Hematol. 2010;89(10):953-8. https://doi.org/10.1007/s00277-010-0980-7.

47. Lulli V, Romania P, Morsilli O, Cianciulli P, Gabbianelli M, Testa U, et al. MicroRNA-486-3p regulates gamma-globin expression in human erythroid cells by directly modulating BCL11A. PLoS One. 2013;8(4):e60436. https:// doi.org/10.1371/journal.pone.0060436. 